\title{
Glandular Malignant Peripheral Nerve Sheath Tumor
}

National Cancer Institute

\section{Source}

National Cancer Institute. Glandular Malignant Peripheral Nerve Sheath Tumor. NCI

Thesaurus. Code C6560.

A variant of malignant peripheral nerve sheath tumor characterized by the presence of glandular epithelium. 